\title{
Assessment of the relationship between follicular fluid calcium ion concentration and reproductive outcomes
}

\author{
Özkan Özdamar ${ }^{1 *}$, İsmet Gün ${ }^{2}$, Serdar Hira ${ }^{2}$, Belgin Devranoğlu ${ }^{2}$
}

\author{
${ }^{1}$ Department of Obstetrics and Gynecology, Gölcük Military Hospital, Kocaeli, Turkey \\ ${ }^{2}$ Department of Obstetrics and Gynecology, Zeynep Kamil Maternity and Children's Hospital, Istanbul, Turkey
}

Received: 30 September 2015

Accepted: 2 November 2015

\author{
*Correspondence: \\ Dr. Özkan Özdamar, \\ E-mail: ozkan_ozdamar35@hotmail.com
}

Copyright: (c) the author(s), publisher and licensee Medip Academy. This is an open-access article distributed under the terms of the Creative Commons Attribution Non-Commercial License, which permits unrestricted non-commercial use, distribution, and reproduction in any medium, provided the original work is properly cited.

\begin{abstract}
Background: Quantification of follicular fluid (FF) composition can provide valuable information about the oocyte state which can be helpful in distinguishing high and low quality oocyte. In the absence of appropriate calcium signaling at fertilization, the embryo may fail to implant and/or develop to full term. We herein aimed to investigate whether FF levels of $\mathrm{Ca}^{2+}$ ion concentrations vary between patients who achieved pregnancy and those who did not following a standard ICSI treatment regimen, and hence to determine whether FF $\mathrm{Ca}^{2+}$ levels could predict reproductive outcomes in patients undergoing ICSI.

Methods: Patients seeking treatment for solely unexplained infertility were recruited in the period between June and December 2013 and were assigned to the groups according to their reproductive outcomes. Group 1 consisted of patients who conceived and Group 2 consisted of those who did not achieve pregnancy following ICSI. Parametric comparisons were performed using Student's t-test. Categorical data were evaluated by using $\chi^{2}$ test.

Results: Groups 1 and 2 consisted of 34 and 66 patients, respectively. Although FF $\mathrm{Ca}^{2+}$ ion concentrations were higher in those who did not achieve any pregnancy, the difference did not reached to statistical significance level $(7.6 \pm 0.4 \mathrm{mg} / \mathrm{dl}$ and $7.9 \pm 0.9 \mathrm{mg} / \mathrm{dl}$ respectively, $\mathrm{p}=0.070)$.

Conclusions: FF $\mathrm{Ca}^{2+}$ ion concentrations did not significantly differ between patients who achieved pregnancy and who did not followed ICSI attempts. Thus FF $\mathrm{Ca}^{2+}$ levels do not appear to be of benefit in predicting reproductive outcomes in unexplained infertility patients undergoing ICSI cycles.
\end{abstract}

Keywords: Follicular fluid, Calcium, Oocyte, ICSI, Reproductive outcomes

\section{INTRODUCTION}

Despite significant advances in the field of reproductive medicine success rate still remain relatively low with clinical pregnancy rates at $33 \% .^{1}$ All attempts assisted in reproduction to improve pregnancy rates as well as to reduce the possibility of multiple pregnancy is to choose the best quality embryo for transfer and to allow implantation of a single embryo. ${ }^{2}$ Despite the importance of oocyte quality, current assessment of oocytes in assisted reproduction is limited and a variety of methods including oocyte morphology studies, ${ }^{3}$ molecular and genetic methods ${ }^{4}$ and polar body biopsies ${ }^{5}$ are being employed for oocyte selection. However, most of these techniques are not applicable in the current practice since they are complicated, expensive and time-consuming ${ }^{6}$ and an optimum technique to determine the best quality oocyte is at this time is still lacking. On the other hand the identification and quantification of follicular fluid (FF) composition can provide valuable information about the oocyte state which can be helpful in distinguishing those oocytes that have a greater capacity to be fertilized and to develop properly. 
It has long been known that calcium is an indispensable signal for mammalian fertilization ${ }^{7}$ and upon the fusion of the sperm and oocyte membranes the first intracellular signalling event observed is a series of low-frequency oscillations and large transient increase in cytoplasmic free $\mathrm{Ca}^{2+}$ ions. The initiation of calcium oscillations is considered to be triggered by the sperm factor phospholipase C zeta (PLCz), which is released into the oocyte following oocyte fertilization. ${ }^{8,9} \mathrm{PLCz}$ triggers a cascade of reactions which finally activates the receptors located on the membrane of the endoplasmic reticulum leading to the cytoplasmic release of calcium. ${ }^{10,11}$ It is presumable that the absence or aberrant of calcium oscillations at the time of fertilization could lead to failed or low fertilization following ICSI. In addition, the contribution of external calcium influx to the intracellular calcium release has been evaluated. Some authors reported that in some species eggs are primarily activated by calcium ions which enter the cytosol from the medium and response to depolarization of the egg's plasma membrane. ${ }^{12}$ In humans the pathways leading to $\mathrm{Ca}^{2+}$ increase within the egg are still vigorously debated.

Elevated $\mathrm{Ca}^{2+}$ plays a vital role as an intracellular messenger in all cells and the $\mathrm{Ca}^{2+}$ signal occurring in the oocyte at fertilization triggers the subsequent events that mediate early embryo development. ${ }^{13}$ In the absence of appropriate calcium signalling at fertilization the embryo may fail to implant and/or develop to full term. ${ }^{14}$ Now FF bathes the developing oocytes and the composition of FF may be regarded as the surrogate for the oocyte quality as it appears to be plausible to investigate a possible association between $\mathrm{FF} \mathrm{Ca}^{2+}$ of reproductive outcomes and pregnancy rates. However, there is a paucity of literature reporting this relationship. In the present study, we aimed to investigate whether FF levels of $\mathrm{Ca}^{2+}$ ion concentrations vary between patients who achieved pregnancy and those who did not followed a standard ICSI treatment regimen and hence to determine whether FF $\mathrm{Ca}^{2+}$ levels could be used as a predictor of reproductive outcomes in patients undergoing ICSI cycles.

\section{METHODS}

A prospective cross-sectional study was initiated at Assisted Reproduction and Infertility Department of Zeynep Kamil Training and Educational Hospital, Istanbul, Turkey. Ethical Board approval was obtained prior to the initiation of the study. Patients seeking treatment for solely unexplained infertility were recruited in a 6 month period between June and December 2013. Unexplained infertility was diagnosed in patients with normal ovulatory cycles, basal hormone profile, semen analysis, TVS and HSG for >12 months. Inclusion criteria follows age between 23-39 years, body mass index $(\mathrm{BMI}) \leq 28 \mathrm{~kg} / \mathrm{m} 2, \quad \mathrm{FSH} \leq 10 \mathrm{mIU} / \mathrm{mL}$ and unexplained infertility patients who underwent either agonist or antagonist protocol. Patients with male or tubal factor infertility were excluded.
All patients underwent through standardized IVF treatment protocol. Gonadotropine doses were individualized according to age, BMI, basal hormone levels, AFC and previous experiences. Gonadotropin stimulation was achieved either by rFSH or hMG. All patients were administered acetyl-salicylic acid $100 \mathrm{mg}$ daily and folic acid $400 \mathrm{mcg}$ daily simultaneously with the start of the protocol.

Serial ultrasonography controls and E2 level measurements was made until 3 follicles $\geq 17 \mathrm{~mm}$ and a serum E2 level $>500 \mathrm{pg} / \mathrm{ml}$ were detected. Choriogonadotropin alpha $250 \mu \mathrm{g}$ s.c. (Ovitrelle $\AA$; Merck Serono, Italy) was administered to induce final follicular maturation. Transvaginal ultrasound-guided oocyte retrieval was performed 35-36 hours after hCG administration. FFs collected from the first punctured MII oocyte containing mature $(>17 \mathrm{~mm})$ follicle at the first entry without contamination was analyzed whereas FFs contaminated with blood were not used. All patients were implemented with single dose of cefazolin sodium (Sefazol, Mustafa Nevzat İlaç San., Turkey) 1 gr, i.m at the course of OPU procedure and were given doxycycline $100 \mathrm{mg}$ capsule (Tetradox capsule, Fako Ilaç, Turkey) twice daily and methylprednisolone $16 \mathrm{mg}$ capsule (Prednol tablet, Mustafa Nevzat İlaç San., Turkey) once daily orally and continued for 4 days.

The aspirated FFs were centrifuged for 10 minutes at $2000 \times \mathrm{g}$ at room temperature and separated supernatant fluids were assayed for $\mathrm{Ca}^{2+}$ ion concentrations. All patients underwent ICSI in which a single embryo transfer was performed on either 2nd or 3rd day. Patients were assigned to the groups according to the reproductive outcomes .Group 1 consisted of patients who conceived and Group 2 consisted of those who did not achieve pregnancy following the treatment. Achievement of pregnancy was defined as a positive pregnancy test result $(\beta$-hCG levels $>20 \mathrm{mIU} / \mathrm{ml}) 12$ days after embryo transfer. The results of $\mathrm{Ca}^{2+}$ ion concentrations for two groups were compared.

Statistical analyses were performed using the statistical Package for the Social Sciences for Windows 15.0 software (SPSS, Chicago, IL., USA). Descriptive statistics were given as mean and standard deviation. Parametric comparisons were performed using Student's t-test. Categorical data were evaluated by using $\chi^{2}$ test. Statistical significance was defined as $\mathrm{p}<0.05$.

\section{RESULTS}

From June to December 2013 a total of 100 women with the diagnosis of unexplained infertility were included in the study. Group 1 consisted of 34 and Group 2 consisted of 66 patients. Demographic and induction characteristics are presented in Table 1. None of the demographic characteristics significantly differed between the groups. 
Although $\mathrm{FF} \mathrm{Ca}{ }^{2+}$ ion concentrations were higher in those who did not achieve any pregnancy, the difference did not reached to statistical significance level $(7.6 \pm 0.4 \mathrm{mg} / \mathrm{dl}$ and $7.9 \pm 0.9 \mathrm{mg} / \mathrm{dl}$, respectively, $\mathrm{p}=0.070)$.

Table 1: Demographic and stimulation characteristics and treatment outcomes of the groups.

\begin{tabular}{|llll|}
\hline & Group 1 $(\mathrm{n}=34)$ & Group 2 $(\mathrm{n}=66)$ & $\mathrm{p}$ \\
\hline Age, $\mathrm{y}$ & $32.3 \pm 4.3$ & $31.7 \pm 4.7$ & $0.586^{\mathrm{a}}$ \\
\hline BMI, $\mathrm{kg} / \mathrm{m} 2$ & $24.0 \pm 3.9$ & $24.7 \pm 3.5$ & $0.430^{\mathrm{a}}$ \\
\hline Infertility duration, $\mathrm{y}$ & $5.4 \pm 2.8$ & $6.0 \pm 3.5$ & $0.371^{\mathrm{a}}$ \\
\hline D3 FSH, IU/l & $7.8 \pm 2.4$ & $8.0 \pm 2.7$ & $0.644^{\mathrm{a}}$ \\
\hline D3 estradiol, pg/ml & $52.2 \pm 22.3$ & $50.2 \pm 19.2$ & $0.654^{\mathrm{a}}$ \\
\hline GnRH agonist/antagonist protocol, $\mathrm{n}$ & $12 / 22$ & $24 / 42$ & $0.916^{\mathrm{b}}$ \\
\hline Total dose of gonadotropin, IU & $2616.5 \pm 1363.4$ & $2768.6 \pm 1124.6$ & $0.521^{\mathrm{a}}$ \\
\hline Serum E2 on HCG day, pg/ml & $2030.2 \pm 1581.2$ & $1723.4 \pm 787.6$ & $0.216^{\mathrm{a}}$ \\
\hline Total oocytes retrieved, $\mathrm{n}$ & $7.6 \pm 4.6$ & $7.3 \pm 4.4$ & $0.767^{\mathrm{a}}$ \\
\hline MII oocytes, $\mathrm{n}^{2+}$ & $5.9 \pm 3.4$ & $5.2 \pm 3.8$ & $0.353^{\mathrm{a}}$ \\
\hline $\mathrm{Ca}^{2}$ in follicular fluid, & $7.6 \pm 0.4$ & $7.9 \pm 0.9$ & $0.070^{\mathrm{a}}$ \\
\hline
\end{tabular}

Data are presented as mean \pm SD and number; ${ }^{a}$ Student $t$-test; ${ }^{b} \chi 2$ test.

\section{DISCUSSION}

$\mathrm{Ca}^{2+}$ is universally accepted as the essential trigger of egg activation. The importance of $\mathrm{Ca}^{2+}$ during the process of oocyte maturation and fertilization has been confirmed in numerous studies conducted in mammalian and nonmammalian animal species. The detailed signal transduction pathways that lead to the intracellular $\mathrm{Ca}^{2+}$ liberation during hormonal and sperm stimulation have been extensively studied. ${ }^{15,16}$ Recently a higher intracellular $\mathrm{Ca}^{2+}$ concentrations in granulosa cells have been reported to increase the fertilization ratio and oocyte quality in patients undergoing IVF. ${ }^{17}$ Hence we postulated that a higher intracellular concentration of $\mathrm{Ca}^{2+}$ could be represented as a higher FF level of $\mathrm{Ca}^{2+}$, which might have help us speculate about reproductive capability of the individual.

The biochemical composition of fluid in mature Graafian follicle is of great importance since this medium constitutes the micromilieu for developing oocytes and the composition of FF may have an impact in the oocyte quality which is a crucial parameter in women undergoing assisted reproduction. FF contains substances implicated in oocyte meiosis rupture the follicular wall and fertilization. ${ }^{18,19}$ Numerous metabolites in FF have been investigated in patients undergoing assisted reproduction in recent years. ${ }^{20,21} \mathrm{FF}$ levels of $\mathrm{Ca}^{2+}$ ion in IVF/ICSI patients have been evaluated in a limited number of studies. In one of the study $\mathrm{Ca}^{2+}$ and $\mathrm{Mg}^{2+}$ was reported as the most abundant elements in $\mathrm{FF}^{22}$ In that study it was confirmed that element concentrations in small follicles frequently differed from those of large follicles and that the element concentrations in large follicles more closely resembled those in blood. Azem et $\mathrm{al}^{23}$ examined the serum and preovulatory FF levels of $\mathrm{Ca}^{2+}$ and $\mathrm{Mg}^{2+}$ throughout IVF cycles and sought a possible relationship to IVF/ET. They also concluded that the presence of these divalent cations in the FF indicated their correlation to folliculogenesis and ovulatory processes. Makki et $\mathrm{al}^{24}$ reported that they received the highest percentage of invitro maturation and fertilization when they applied the highest concentrations of selenium, calcium and calcium ionophore concentrations. Here by extrapolated that maturation and activation of oocytes may be triggered by changes in intracellular ion concentrations as second messengers in signal transduction pathways. In a more recent study it was reported that treatment with $\mathrm{Ca}^{2+}$ ionophore improved embryo development and reproductive outcomes in cases with previous developmental problems. ${ }^{25}$ Cleavage to 2cell stage the number of blastocysts formed on day 5 and the rates of implantation, clinical pregnancy and live birth were significantly higher in the ionophore group than in the control group. However to our knowledge there is no study investigating the relationship between $\mathrm{FF} \mathrm{Ca}^{2+}$ ion levels and pregnancy rates in the literature. In what we believe is the first study reporting this relationship. According to the results of our study $\mathrm{FF} \mathrm{Ca}^{2+}$ ion levels do not significantly differ between patients who conceived and those who did not although slightly higher in the latter.

The limitations of the present study include the relatively low patient number and lack of the assessment of intracellular $\mathrm{Ca}^{2+}$ ion levels for its association with $\mathrm{FF}$ levels and pregnancy outcomes. However, further studies with larger patient numbers and designed to evaluate intracellular $\mathrm{Ca}^{2+}$ levels synchronously are warranted.

\section{CONCLUSIONS}

FF $\mathrm{Ca}^{2+}$ ion concentrations do not significantly differ between patients who achieved pregnancy and who did 
not following ICSI attempts. Thus $\mathrm{FF} \mathrm{Ca}^{2+}$ levels do not appear to be benefit in predicting reproductive outcomes in unexplained infertility patients undergoing ICSI cycles.

\section{Funding: No funding sources}

Conflict of interest: None declared

Ethical approval: The study was approved by the Institutional Ethics Committee

\section{REFERENCES}

1. Ferraretti AP, Goossens V, Kupka M, Bhattacharya S, de Mouzon J, Castilla JA, et al. Assisted reproductive technology in Europe, 2009: results generated from European registers by ESHRE. Hum Reprod. 2013;28:2318-31.

2. Haggarty P, Wood M, Ferguson E, Hoad G, Srikantharajah A, Milne E, et al. Fatty acid metabolism in human preimplantation embryos. Hum Reprod .2006;21:766-73.

3. Balaban B, Urman B. Effect of oocyte morphology on embryo development and implantation. Reprod Biomed Online 2006;12:608-15.

4. Patrizio P, Fragouli E, Bianchi V, Borini A, Wells D. Molecular methods for selection of the ideal oocyte. Reprod Biomed Online. 2007; 15:346-53.

5. Dawson A, Griesinger G, Diedrich K. Screening oocytes by polar body biopsy. Reprod Biomed Online. 2006;13:104-9.

6. Revelli A, Piane LD, Casano S, Molinari E, Massobrio M, Rinaudo P. Follicular fluid content and oocyte quality: from single biochemical markers to metabolomics. Reprod Biol Endocrinol .2009; 7:40.

7. Nikiforaki D, Vanden Meerschaut F, Qian C, De Croo I, Lu Y, Deroo $\mathrm{T}$, et al. Oocyte cryopreservation and in vitro culture affect calcium signalling during human fertilization. Hum Reprod 2014;29(1):29-40.

8. Kashir J, Heindryckx B, Jones C, De Sutter P, Parrington J, Coward K. Oocyte activation, phospholipase $\mathrm{C}$ zeta and human infertility. Hum Reprod Update. 2010;16:690-703.

9. Nomikos M, Swann K, Lai FA. Starting a new life: sperm PLC-zeta mobilizes the $\mathrm{Ca} 2+$ signal that induces egg activation and embryo development: an essential phospholipase $\mathrm{C}$ with implications for male infertility. Bioessays .2012;34:126-34.

10. $\mathrm{Xu} \mathrm{Z}$, Kopf GS, Schultz RM. Involvement of inositol 1,4,5-trisphosphate-mediated $\mathrm{Ca}^{2+}$ release in early and late events of mouse egg activation. Development .1994;120:1851-9.

11. Yu Y, Nomikos M, Theodoridou M, Nounesis G, Lai FA, Swann K. PLCz causes $\mathrm{Ca}^{(2+)}$ oscillations in mouse eggs by targeting intracellular and not plasma membrane PI(4,5)P(2). Mol Biol Cell. 2012;23:37180 .
12. Jaffe JL. Sources of calcium in egg activation: a review and hypothesis. Dev Biol. 1983;99(2):265-76.

13. Hogben M, Parrington J, Shevchenko V, Swann K, Lai FA. Calcium oscillations, sperm factors and egg activation at fertilisation. J Mol Med (Berl). 1998;76(8):548-54.

14. Ducibella T, Schultz RM, Ozil JP. Role of calcium signals in early development. Semin Cell Dev Biol. 2006;17:324-32.

15. Santella L, Puppo A, Chun JT. The role of the actin cytoskeleton in calcium signaling in starfish oocytes. Int J Dev Biol .2008;52(5-6):571-84.

16. Santella L, Chun JT. Actin, more than just a housekeeping protein at the scene of fertilization. Sci China Life Sci. 2011;54:733-43.

17. Tola EN, Mungan MT, Uğuz AC, Naziroğlu M. Intracellular $\mathrm{Ca} 2+$ and antioxidant values induced positive effect on fertilisation ratio and oocyte quality of granulosa cells in patients undergoing in vitro fertilisation. Reprod Fertil Dev. 2013;25(5):746-52.

18. Tsafriri A. Ovulation as a tissue remodelling process. Proteolysis and cumulus expansion. Adv Exp Med Biol. 1995;377:121-40.

19. Tsafriri A, Reich R. Molecular aspects of mammalian ovulation. Exp Clin Endocrinol Diabetes. 1999;107:1-11.

20. Wallace M, Cottell E, Gibney MJ, McAuliffe FM, Wingfield M, Brennan L. An investigation into the relationship between the metabolic profile of follicular fluid, oocyte developmental potential, and implantation outcome. Fertil Steril. 2012;97:107884.

21. Özdamar Ö, Gün İ, Ertuğrul SS, Özden O, Sofuoğlu $\mathrm{K}$. Does biochemical profile of follicular fluid in women undergoing assisted reproduction vary between the right and left ovaries?. Int J Reprod Contracept Obstet Gynecol .2015;4:1066-9.

22. Silberstein T, Saphier O, Paz-Tal O, Gonzalez L, Keefe DL, Trimarchi JR. Trace element concentrations in follicular fluid of small follicles differ from those in blood serum, and may represent long-term exposure. Fertil Steril. 2009;91(5):1771-4.

23. Azem F, Hanannel A, Wolf Y, Ben-Yosef D, Wagman I, Yovel I, et al. Divalent cation levels in serum and preovulatory follicular fluid of women undergoing in vitro fertilization embryo transfer. Gynecol Obstet Invest. 2004;57(2):86-9.

24. Makki M, Saboori E, Sabbaghi MA, Aram R, Fallahian MH, Peyghambari F, et al. Effects of selenium, calcium and calcium ionophore on human oocytes in vitro maturation in a chemically defined medium. Iran J Reprod Med. 2012;10(4):343-8.

25. Ebner T, Oppelt P, Wöber M, Staples P, Mayer RB, Sonnleitner U, et al. Treatment with $\mathrm{Ca} 2+$ ionophore improves embryo development and outcome in cases with previous developmental problems: a prospective multicenter study. Hum Reprod 2015;30(1):97-102.

Cite this article as: Özdamar Ö, Gün İ, Hira S, Devranoğlu B. The assessment of the relationship between follicular fluid calcium ion concentration and reproductive outcomes. Int J Reprod Contracept Obstet Gynecol 2015;4:1984-7. 